\title{
Research Paper: Effect of Different Cognitive Loads on Gait Stability in Younger and Older Adults
}

\author{
Masoud Mirmoezzi ${ }^{1}$ Q, Mahdi Namazizadeh ${ }^{2 *}$ Q Heydar Sadeghi $^{3}$ Q Fariba Mohammadi $^{4} \mathbf{P}$ \\ 1. Department of Motor Behavior, Faculty of Physical Education and Sport Sciences, Central Tehran Branch, Islamic Azad University, Tehran, Iran \\ 2. Department of Physical Education and Sport Science, Faculty of Physical Education and Sports Sciences, Khorasgan Branch, Islamic Azad University, \\ Isfahan, Iran. \\ 3. Department of Sport Biomechanics, Kinesiology Research Center, Kharazmi University, Tehran, Iran. \\ 4. Sports Sciences Research Institute of Iran (SSRII), Tehran, Iran.
}

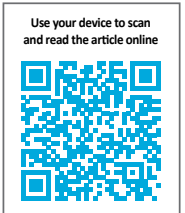

Citation Mirmoezzi M, Namazizadeh M, Sadeghi H, Mohammadi F. Effect of Different Cognitive Loads on Gait Stability in Younger and Older Adults. Physical Treatments. 2019; 9(2):69-76. http://dx.doi.org/10.32598/ptj.9.2.69

d of" http://dx.doi.org/10.32598/ptj.9.2.69

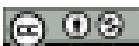

Article info:

Received: 10 Dec 2018

Accepted: 28 Feb 2019

Available Online: 01 Apr 2019

Keywords:

Walking, Cognitive

Function, Balance

\section{A B S T RA C T}

Purpose: As many older people fall during dual tasks, we aimed to examine the effect of different cognitive loads on learning gait stability in younger and older adults.

Methods: 10 younger (Mean \pm SD age: $25.91 \pm 3.42$ years) and 10 older adults (Mean \pm SD: $66.65 \pm 4.28$ years) were healthy volunteers without a history of falls. They were asked to do three tasks on a treadmill with cognitive load (none, simple, and complex). The Gait-stability Ratio (GSR) was calculated in each condition. Two-way repeated-measures ANOVA was used to examine the mean differences at a significance level of 0.05 .

Results: The findings showed that high cognitive load behavior during preferred speed walking in the younger and older adults decreases walking speed, and subjects learn to achieve greater stability. It was determined that by applying different cognitive loads (none, simple, and complex), the GSR value in older adults was higher than younger adults $(\mathrm{P}<0.01)$.

Conclusion: The results showed that the older adults, through different walking strategies, especially the lowering phase, provide double support while walking so that they fall less with increasing steadiness. Also, walking exercises along with complex cognitive load can help older adults to better motor control.

\footnotetext{
* Corresponding Author:
}

Mahdi Namazizadeh, PhD.

Address: Department of Physical Education and Sport Science, Faculty of Physical Education and Sports Sciences, Khorasgan Branch, Islamic Azad University, Esfahan, Iran.

Phone: +98 (912) 6825007

E-mail: namazizadehmahdi@gmail.com 


\section{Highlights}

- In a dynamic system, additional cognitive conditions increase the control effort, while the control system tries to reduce the control effort on the system.

- Control capacity is limited, and the system uses different mechanisms to compensate for this disorder, which is more tangible among the youth with better performance.

- Older adults use more support while walking by using different strategies, especially the lowering phase that by increasing in gait stability ratio, the odds of falling decreases.

\section{Plain Language Summary}

The natural aging process endangers older adults with a higher risk of falling while walking. A dual-task situation may affect walking performance. In this study, we found out that complex cognitive load exercises during preferential walking in the younger and older adults would decrease walking speed and increase learning gait stability. The gait stability ratio in older adults is higher than that in young adults to achieve greater balance.

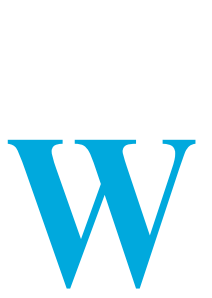

\section{Introduction}

alking is generally viewed as an automated, smooth, rhythmic motor task. With advancing age, reduced function of different systems used for walking may affect walking ability and increase risk of falling. Studies of the ability to walk while performing simultaneous tasks show that the dependence of sensorimotor control on cognitive processes increases with advancing age [1]. A dual-task situation may either affect walking performance, a second activity, or both, depending on individual resources, priorities, and the complexity of the tasks [2]. Change in gait patterns related to Dual Tasking (DT), identified as a Dual-task Cost (DTC), can be attributed to competition for limited resources in the Central Nerve System (CNS) in older people even when they are healthy $[1,3]$.

It can also increase gait stability and reduce the risk of a fall by changing the strategies needed to address high-level attention and task demands [1]. To maintain efficiency and smoothness in walking, the Central Nerve System (CNS) should consider changes in control strategies [4]. According to recent studies, walking in older people is not an automatic process. Because if it were an automated process, it would not be possible to make changes in the gait pattern and gait speed in the presence of attention demands and the cognitive load $[2,3]$. Instead, many studies have shown that DT affect walking speed and decreases with a cognitive load while walking, walking speed, and gait stability $[1,5,6]$.
Secondary tasks taken during walking can be put into general categories of motor and cognitive tasks. Among these tasks, the secondary motor task reduces the protective reflexes of the upper extremities for the purpose of requiring high-level motor coordination. Also, when considering attention needs, the use of secondary tasks that have a purely cognitive aspect seems more appropriate than the motor task, which consists of a combination of motor and cognitive aspects [4].

The cognitive load is the mental resource needed to perform the task. An increase in the cognitive load in different tasks while walking (such as counting) imposes a different cognitive load on the central processing system [7]. According to the theory of capacity sharing in the dual-task paradigm, implementing additional tasks in walking may change walking features or the implementation of the second task or both [8]. Dubost et al. reported an increase in walking variability in the elderly while performing simple computational tasks [9]. Lindenberg et al. found that dual-task disorders increased with age, and disorders such as a decrease in walking speed and an increase in the number of wrong steps during walking seemed to appear [10]. However, changes in the natural level can lead to unstable motion and an increased risk of falling [11].

It seems that DT walking, which in many cases is cognitive, involves the individual. These factors can affect stability while walking and falling in a person. Most daily activities need doing more than one activity, such as walking and talking. Some of the fall cases in the elderly occur when there is a need to focus on controlling 
posture and performing cognitive tasks simultaneously. Knowledge about motor control in healthy people can be used as a base for comparing the mechanism of disease change. The use of dual cognitive tasks seems useful and can be used both in the identification of the population at risk and in the evaluation of the results of rehabilitation programs for preventing falls in the elderly. However, no studies have examined the effect of different cognitive loads on gait stability in healthy younger and older adults simultaneously. To address this issue, we are looking for the answer to the question "what is the effect of different cognitive load on gait stability"?

\section{Materials and Methods}

\section{Subjects}

This study adopted a causal-comparative design. The statistical population consisted of university staff. Ten younger adults (Mean \pm SD age of $25.91 \pm 3.42$ years with Mean \pm SD BMI of $24.10 \pm 2.33 \mathrm{~kg} / \mathrm{m}^{2}$ ) and 10 healthy older adults (Mean \pm SD age of $66.65 \pm 4.28$ years with Mean \pm SD BMI of $26.56 \pm 2.35 \mathrm{~kg} / \mathrm{m}^{2}$ ) were healthy volunteers of this study without a history of falls (sample size suggested by Byrne et al. with $80 \%$ power efficiency to detect group differences at 0.05 level) [12]. All participants were healthy and able to walk for at least 90 seconds without the help and understanding of the verbal instructions. If they had neurological, musculoskeletal, visual, auditory, vestibular, or neural disorders that affected walking or reducing the cognitive score, they would be excluded from the study. The older adults acquired a mini-mental state examination score of 24 or higher [13]. All the individuals completed the informed consent form before their participation. The approval of the Ethics Committee of Kharazmi University Research was issued under the number 100.1000-K.A.P.

\section{Walking task}

A treadmill (HP-cosmos Mercury ${ }^{\circledR M}$ Med, Germany) with two piezoelectric force plates of Kistler Company was used for walking. These force plates can output the number of steps, step length, cadence, and walking speed [7]. The participants conducted a treadmill test at the preferred speed with bare feet at speeds of one $\mathrm{km} / \mathrm{h}$ and a gradual increase of $0.5 \mathrm{~km} / \mathrm{h}$ to the speed stated by the participant [14]. After recording the speed, the participants were again asked to step on the treadmill and confirm their desired speed at their preferred speed determined by them with a $0.5 \mathrm{~km} / \mathrm{h}$ speed decrease or increase [15]. This method was repeated four times, and eventually, the preferred speed of each participant was determined. For each participant, walking tasks were done three times at the preferential speed with cognitive load (none, simple and complex). The data were recorded on the treadmill for 90 seconds $[4,16]$. For the acquaintance of the participants with the laboratory environment and the test, after a full description of the test, each participant practiced on a treadmill experiment several times. The time needed to rest between the tests was given to the individuals. Safety considerations (Harness) were observed during the test.

\section{Cognitive task}

The cognitive task of the study was the mental calculation task. The mental calculation task involves working memory and subtracting three by three (complex cognitive task) or one by one (simple cognitive task) from a random three-digit number, which continued for $90 \mathrm{sec}$ onds [17]. In the non-cognitive task, the subjects underwent a treadmill at their preferred speed for 90 seconds [4]. The participants were asked to do a cognitive task while sitting on the chair and or moving on the treadmill, and their points were recorded. Intervals, words, or false calculations were recorded for each of these tests. Meanwhile, all speech tests were recorded with a tape recorder. The participants did not have any previous training on this task. As subjects performed the tasks for 90 seconds, they had little learning effect on subjects. The Cognitive Performance Scale (CPS) was calculated by Formula 1.

$$
\begin{aligned}
& \text { Formula (1) } \\
& C P S=\frac{C R R_{\text {Task in sitting position }}-C R R_{\text {Task in dual-task walking }}}{C R R_{\text {Task in sitting position }}}
\end{aligned}
$$

The cognitive task was made to changes in Correct Response Rate (CRR) (Formula 2) because of the dualtask to individual conditions. In this study, the cognitive function score was calculated for each task based on the Formula $1[4,18]$.

\section{Formula (2)}

$C R R=$ Response rate per second $\times$ Percent of correct answers response

\section{Gait stability}

Measurements were stated with respect to walking speed, and step length changes were expressed by Cromwell et al. [19]. This size includes GSR, which is a cadence ratio (steps per second) to speed $(\mathrm{m} / \mathrm{s})$, whose unit is steps per meter. GSR expresses gait stability, and 
its increase shows the increase of steps per meter, meaning that the person has a double support level and better gait stability. The researchers stated that this method had good validity and could be used to evaluate and measure gait stability in the dynamic movement. They reported the reliability of the test through intraclass correlation coefficient method for walking speeds as 0.91 and for a cadence as 0.75 [19]. The test-retest reliability using the correlation coefficient for GSR was 0.81 in this study.

\section{Statistical analysis}

The Kolmogorov-Smirnov test checked the correlation of the frequency distribution of quantitative variables with normal theoretical distribution. Two-way repeated measures ANOVA evaluated the main and interactive effects of the group and cognitive load on dependent variables with a 95\% confidence level and Bonferroni posthoc test.

\section{Results}

Table 1. Descriptive characteristic of participants
Table 1 presents the individual characteristics of the participants. According to the Kolmogorov-Smirnov test, the data were normally distributed ( $P \geq 0.05$ ). Figure 1 shows the mean CPS in adult and elderly groups at preferred walking speeds. Using this score, the speed and precision of a person's cognitive task are taken into account. The higher CPS indicates the weaker person's cognitive performance (less correct answer) while dualtask walking and vice versa. The elderly seem to have complicated cognitive and weaker CPS (Figure 1).

Table 2 presents the mean of the parameters involved in gait stability at different cognitive loads. The results of two-way repeated measures ANOVA for GSR show a significant difference between the younger and the older adult groups $\left(\mathrm{F}_{1,2}=15.64, \mathrm{P}=0.001\right)$. There is also a significant difference in the cognitive load for GSR $\left(\mathrm{F}_{2}\right.$, $=26.47, \mathrm{P}=0.024)$.

Comparison of means by post hoc test showed that complex cognitive load in the older adults was signifi-

\begin{tabular}{|c|c|c|c|}
\hline Group & No. Gender & Characteristics & Mean \pm SD \\
\hline \multirow{4}{*}{ Younger adults } & \multirow{4}{*}{$\begin{array}{c}5 \text { men } \\
5 \text { women }\end{array}$} & Age (y) & $25.91 \pm 3.42$ \\
\hline & & Height (m) & $1.68 \pm 0.03$ \\
\hline & & Weight (kg) & $65.68 \pm 1.30$ \\
\hline & & BMI $\left(\mathrm{kg} / \mathrm{m}^{2}\right)$ & $24.11 \pm 2.33$ \\
\hline \multirow{4}{*}{ Older adults } & \multirow{4}{*}{$\begin{array}{c}5 \text { men } \\
5 \text { women }\end{array}$} & Age (y) & $66.65 \pm 4.28$ \\
\hline & & Height (m) & $1.60 \pm 0.02$ \\
\hline & & Weight (kg) & $69.59 \pm 3.89$ \\
\hline & & BMI $\left(\mathrm{kg} / \mathrm{m}^{2}\right)$ & $26.56 \pm 2.35$ \\
\hline
\end{tabular}

SD: Standard Deviation; BMI: Body Mass Index

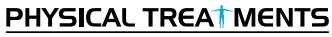

Table 2. Mean $\pm S D$ of parameters involved in gait stability with different cognitive loads

\begin{tabular}{|c|c|c|c|c|c|c|}
\hline \multirow[b]{2}{*}{ Cognitive Load } & \multirow[b]{2}{*}{ Participants } & \multicolumn{5}{|c|}{ Mean $\pm S D$} \\
\hline & & $\begin{array}{l}\text { Cadence (Step/ } \\
\text { Second) }\end{array}$ & Velocity (m/s) & GSR (Step/Meter) & Step Length ( $\mathrm{m}$ ) & Double Support (s) \\
\hline \multirow{2}{*}{ None } & YA & $1.85 \pm 0.22$ & $1.42 \pm 0.29$ & $1.30 \pm 0.24$ & $0.72 \pm 0.04$ & $0.63 \pm 0.12$ \\
\hline & $\mathrm{OA}$ & $1.72 \pm 0.12$ & $1.20 \pm 0.18$ & $1.43 \pm 0.14$ & $0.59 \pm 0.09$ & $0.85 \pm 0.21$ \\
\hline \multirow{2}{*}{ Simple } & YA & $1.86 \pm 0.18$ & $1.42 \pm 0.19$ & $1.31 \pm 0.26$ & $0.72 \pm 0.06$ & $0.64 \pm 0.09$ \\
\hline & $\mathrm{OA}$ & $1.70 \pm 0.12$ & $1.19 \pm 0.21$ & $1.42 \pm 0.23$ & $0.58 \pm 0.08$ & $0.87 \pm 0.10$ \\
\hline \multirow{2}{*}{ Complex } & YA & $1.89 \pm 0.19$ & $1.41 \pm 0.32$ & $1.34 \pm 0.15$ & $0.70 \pm 0.16$ & $0.65 \pm 0.01$ \\
\hline & $\mathrm{OA}$ & $1.73 \pm 0.26$ & $1.18 \pm 0.20$ & $1.46 \pm 0.22$ & $0.54 \pm 0.17$ & $0.93 \pm 0.27$ \\
\hline
\end{tabular}

S: Second; M: Meter; YA: Younger Adults; OA: Older Adults

PHYSICAL TREA $\ M E N T S$ 


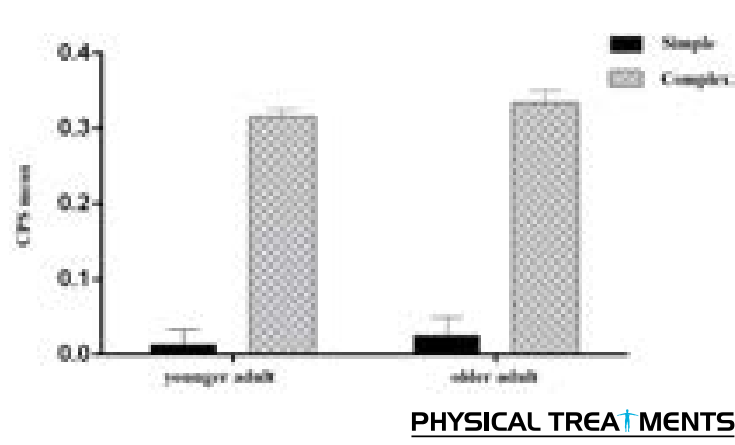

Figure 1. CPS mean in younger and older adults groups with preferred walking speeds

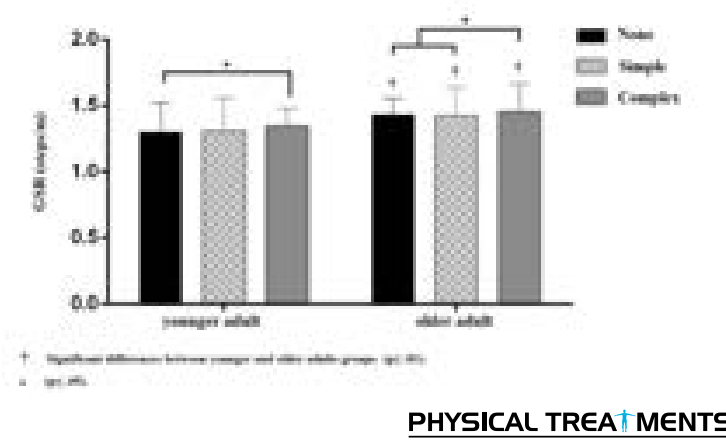

Figure 2. The results of the Bonferroni test with different cognitive loads on GSR in younger and older adults

Table 3. Results of tow-way repeated measures ANOVA for GSR

\begin{tabular}{cccccc}
\hline Sources & Sum of Squares & df & Mean of Squares & F & Sig. \\
\hline Group & 3.13 & 1 & 3.13 & 15.64 & 0.001 \\
Cognitive load & 4.11 & 2 & 2.06 & 26.47 & 0.024 \\
Error & 7.24 & 2 & 3.62 & & \\
\hline
\end{tabular}

PHYSICAL TREA $\ M E N T S$

cantly different from cognitive (simple and none) in younger adults $(\mathrm{P} \leq 0.05)$, and at the time of complex cognitive load, gait stability is more in the older adults. Also, in younger adults, complex cognitive load has a significant difference with/without cognitive load $(\mathrm{P} \geq 0.05)$. The results show a significant difference between older and younger adults in different cognitive loads $(\mathrm{P} \leq 0.01)$ (Table 3). The older adult seems to be more successful in learning gait stability (Figure 2).

\section{Discussion}

The natural aging procedure renders the elderly with a higher risk of falling mostly during walking [20]. Therefore, understanding the mechanism of different cognitive load effects on gait stability in younger and older adults is essential. The results showed that complex cognitive load exercises during preferential walking in the younger and older adults led to a decrease in walking speed and increase in learning gait stability. It was determined that by different cognitive loads (none, simple and complex), the GSR value in older adults is more than younger adults. Cromwell et al. argued that GSR levels were higher in the elderly, meaning that the elderly took more steps in the same distance; so, their gait stability increased with this mechanism. An increase in gait stability while walking makes the elderly compensate for reduction in balance to some extent.
Thus, by maximizing gait stability, the elderly create a pattern of motion that provides greater resistance to disorder, acting as a mechanism for protection against fall [19]. However, this mechanism reduces the forward speed of the elderly, and seems that the speed is sacrificed for stability while stepping. By controlling the movement of the lower limb joints, CNS adapts the walking pattern and, thus, reduces walking speed [19]. It seems that the speed is being sacrificed for gait stability, and the older adult will pay more attention to walk than the younger adult $[2,6,9]$. Thus, walking turns into a complex multi-tasking behavior from a rhythmic and automated behavior, whose control is more difficult that makes the person more likely to fall [6].

This difference was also more common while complex cognitive tasks are done simultaneously. Hall et al. stated that the pattern of walking was changing during cognitive tasks [18]. To maintain vertical posture, CNS must integrate sensory input and retrieve weight distribution information from different sensory systems (vision, vestibular, and sensory) and continually regulate the neuromuscular system [21]. Although this process is automatic, using dual tasks, various studies have shown that tasks such as walking at different speeds and performing complex cognitive tasks need sources of attention [9, 22, 23]. Thus, there is always a competition on the limited resources for control of posture and implementation of dual functional and cognitive tasks [24]. 
In old age, the cognitive processes of sensorimotor control become increasingly important, and adaptation in the elderly walking pattern tends towards adopting the necessary strategies to increase gait stability [1]. Although body capacity to move forward reduces, this strategy significantly reduces the likelihood of falling in the elderly by increasing stability [19]. Older adults have less walking speed than the middle-aged and younger groups, and this speed often reduces while dual tasks. There are also variations in walking speeds between the older and younger adults in the normal state and dual-task mode while walking [11]. Speed, step length, and double support are among the significant components in achieving stability and reducing falls among individuals [25].

To maintain efficiency and smoothness in walking, CNS should consider changes in control strategies [4]. As cadence is similar in adults and the elderly, the elderly cover a shorter distance with shorter steps with the same number of steps compared to adults, and this pattern makes the elderly have more time in the double support phase, causing a more stable walking pattern [25]. However, the walking pattern in adults is associated with unstable phases, and this pattern makes adults have more effective steps forward along with the changes in the center of gravity in each step [19], which is consistent with the results of this study.

There are different theories explaining how to respond to dual tasks, including bottleneck theory and the capacitysharing theory $[2,26]$. Some findings suggest that when the subtractions are performed, competition over limited resources becomes more attentive and demands for further coordination and attention from the CNS. This is the ability to focus on the underlying factors in the performance of DT. On the other hand, as the age increases, the ability of the elderly to devote attention decreases, and they have difficulty in implementing DT [2]. Probably the older adult of the present research paid the closest attention to the dual-task and successful implementation of this, which made it possible to increase the amount of time spent on the route and change the main task (gait).

Walking and simultaneously performing complex cognitive tasks, working memory, and sustained attention can explain the implementation of walking along with cognitive tasks (such as three-point deductions) [27]. It seems that the harder the cognitive task, the more the cost of the dual-task for walking and vice versa, which is completely in line with the results of our study [18].
In challenging motion load and DT, control effort increases, and the control system tries to reduce the control effort on the system. This is because the control capacity is limited, and the system uses different mechanisms to compensate for this disorder, which is more tangible among the youth who has better performance. Nonetheless, the older adults create double support while walking by different walking strategies, especially the lowering phase, so that it decreases with increasing in GSR falling $[4,28]$. It seems that the adoption of walking exercises, combined with complex cognitive load in older adults, can provide better motor control. Also, in particular situations where complex synchronous tasks are possible, the best performance of the control system is provided and reduces the risk of falling.

Some elderly, who were physically and mentally ill, did not meet the inclusion criteria of the study because of the inability to perform study cognitive and functional tasks. The researcher did not control the sleep, rest, and nutritional status of the subjects before the tests. The treadmill use could also be a potential limitation for the study as treadmill kept speed walking of the individual constant in all conditions that could artificially alter the natural variability and attention needs of walking. However, as each participant should be tested according to the same controlled conditions and their cognitive load and walking speed, one could state that walking on the ground was different a little from the current measured values, which were among the limitations of the study.

This study demonstrated that in older adults, the cognitive load could significantly alter gait strategies during walking. These changes may indicate the high adaptability of the CNS to modify control strategies to maintain the stability, rhythmicity, and smoothness of walking during challenging conditions.

\section{Ethical Considerations}

\section{Compliance with ethical guidelines}

The research was approved by the Ethics Committee of Kharazmi University under the number of 100.1000-K.A.P.

\section{Funding}

This study was part of the PhD. dissertation of the first author, Department of motor Behavior, Faculty of Physical Education and Sport Sciences, Islamic Azad University, Central Tehran Branch, Tehran, Iran. 


\section{Authors' contributions}

All authors contributed in preparing this article.

\section{Conflict of interest}

The authors declared no conflict of interests.

\section{References}

[1] Nordin E, Moe-Nilssen R, Ramnemark A, Lundin-Olsson L Changes in step-width during dual-task walking predicts falls. Gait \& Posture. 2010; 32(1):92-7. [DOI:10.1016/j.gaitpost.2010.03.012] [PMID]

[2] Hausdorff JM, Schweiger A, Herman T, Yogev-Seligmann G, Giladi N. Dual-task decrements in gait: Contributing factors among healthy older adults. The Journals of Gerontology Series A: Biological Sciences and Medical Sciences. 2008; 63(12):1335-43. [DOI:10.1093/gerona/63.12.1335] [PMID]

[3] Woollacott M, Shumway-Cook A. Attention and the control of posture and gait: A review of an emerging area of research. Gait \& Posture. 2002; 16(1):1-14. [DOI:10.1016/ S0966-6362(01)00156-4]

[4] Ghanavati T, Salavati M, Karimi N, Negahban H, Takamjani IE, Mehravar M, et al. Intra-limb coordination while walking is affected by cognitive load and walking speed. Journal of Biomechanics. 2014; 47(10):2300-5. [DOI:10.1016/j.jbiomech.2014.04.038] [PMID]

[5] Hebenstreit F, Leibold A, Krinner S, Welsch G, Lochmann M, Eskofier BM. Effect of walking speed on gait sub phase durations. Human Movement Science. 2015; 43:118-24. [DOI:10.1016/j.humov.2015.07.009] [PMID]

[6] Lamoth CJ, van Deudekom FJ, van Campen JP, Appels BA, de Vries OJ, Pijnappels M. Gait stability and variability measures show effects of impaired cognition and dual tasking in frail people. Journal of NeuroEngineering and Rehabilitation. 2011; 8:2. [DOI:10.1186/1743-0003-8-2] [PMID] [PMCID]

[7] Taheri M, Irandoust K. The effect of balance exercises and computerized cognitive training on psychomotor performance in elderly. Journal of Physical Therapy Science. 2017; 29(12):2097-9. [DOI:10.1589/jpts.29.2097] [PMID] [PMCID]

[8] Chiu SL, Chou LS. Variability in inter-joint coordination during walking of elderly adults and its association with clinical balance measures. Clinical biomechanics. 2013; 28(4):454-8. [DOI:10.1016/j.clinbiomech.2013.03.001] [PMID]

[9] Dubost V, Kressig RW, Gonthier R, Herrmann FR, Aminian K, Najafi B, et al. Relationships between dual-task related changes in stride velocity and stride time variability in healthy older adults. Human Movement Science. 2006; 25(3):372-82. [DOI:10.1016/j.humov.2006.03.004] [PMID]

[10] Lindenberger U, Marsiske M, Baltes PB. Memorizing while walking: Increase in dual-task costs from young adulthood to old age. Psychology and Aging. 2000; 15(3):417-36. [DOI:10.1037/0882-7974.15.3.417] [PMID]
[11] Hollman JH, Childs KB, McNeil ML, Mueller AC, Quilter $\mathrm{CM}$, Youdas JW. Number of strides required for reliable measurements of pace, rhythm and variability parameters of gait during normal and dual task walking in older individuals. Gait \& Posture. 2010; 32(1):23-8. [DOI:10.1016/j. gaitpost.2010.02.017] [PMID]

[12] Byrne JE, Stergiou N, Blanke D, Houser JJ, Kurz MJ, Hageman PA. Comparison of gait patterns between young and elderly women: An examination of coordination. Perceptual and Motor Skills. 2002; 94(1):265-80. [DOI:10.2466/ pms.2002.94.1.265] [PMID]

[13] Lord SR, Smith ST, Menant JC. Vision and falls in older people: Risk factors and intervention strategies. Clinics in Geriatric Medicine. 2010; 26(4):569-81. [DOI:10.1016/j. cger.2010.06.002] [PMID]

[14] Kang HG, Dingwell JB. Separating the effects of age and walking speed on gait variability. Gait \& Posture. 2008 27(4):572-7. [DOI:10.1016/j.gaitpost.2007.07.009] [PMID]

[15] Buzzi UH, Stergiou N, Kurz MJ, Hageman PA, Heidel J. Nonlinear dynamics indicates aging affects variability during gait. Clinical Biomechanics. 2003; 18(5):435-43. [DOI:10.1016/S0268-0033(03)00029-9]

[16] Chiu SL, Chou LS. Effect of walking speed on inter-joint coordination differs between young and elderly adults. Journal of Biomechanics. 2012; 45(2):275-80. [DOI:10.1016/j. jbiomech.2011.10.028] [PMID]

[17] Gaoua N, Herrera CP, Périard JD, El Massioui F, Racinais S. Effect of passive hyperthermia on working memory resources during simple and complex cognitive tasks. Frontiers in Psychology. 2018; 8:2290. [DOI:10.3389/fpsyg.2017.02290] [PMID] [PMCID]

[18] Hall CD, Echt KV, Wolf SL, Rogers WA. Cognitive and motor mechanisms underlying older adults' ability to divide attention while walking. Physical Therapy. 2011; 91(7):1039-50. [DOI:10.2522/ptj.20100114] [PMID]

[19] Cromwell RL, Newton RA. Relationship between balance and gait stability in healthy older adults. Journal of Aging and Physical Activity. 2004; 12(1):90-100. [DOI:10.1123/ japa.12.1.90]

[20] Beurskens R, Bock O. Age-related deficits of dual-task walking: A review. Neural Plasticity. 2012; 2012:131608. [DOI:10.1155/2012/131608] [PMID] [PMCID]

[21] García RB, Corresa SP, Bertomeu JMB, Suárez-Varela MMM. Static posturography with dynamic tests. usefulness of biomechanical parameters in assessing vestibular patients. Acta Otorrinolaringologica (English Edition). 2012; 63(5):332-8. [DOI:10.1016/j.otoeng.2012.09.003]

[22] Beauchet O, Dubost V, Allali G, Gonthier R, Hermann FR, Kressig RW. 'Faster counting while walking' as a predictor of falls in older adults. Age and Ageing. 2007; 36(4):418-23. [DOI:10.1093/ageing/afm011] [PMID]

[23] Liu-Ambrose T, Katarynych LA, Ashe MC, Nagamatsu LS, Hsu CL. Dual-task gait performance among community-dwelling senior women: The role of balance confidence and executive functions. Journals of Gerontology Series A: Biomedical sciences and medical sciences. 2009; 64(9):975-82. [DOI:10.1093/gerona/glp063] [PMID] 
[24] Boisgontier MP, Beets IA, Duysens J, Nieuwboer A, Krampe RT, Swinnen SP. Age-related differences in attentional cost associated with postural dual tasks: Increased recruitment of generic cognitive resources in older adults. Neuroscience \& Biobehavioral Reviews. 2013; 37(8):1824-37. [DOI:10.1016/j neubiorev.2013.07.014] [PMID]

[25] Osoba MY, Rao AK, Agrawal SK, Lalwani AK. Balance and gait in the elderly: A contemporary review. Laryngoscope Investigative Otolaryngology. 2019; 4(1):143-53. [DOI:10.1002/lio2.252] [PMID] [PMCID]

[26] Ruthruff E, Pashler HE, Klaassen A. Processing bottlenecks in dual-task performance: Structural limitation or strategic postponement? Psychonomic Bulletin \& Review. 2001; 8(1):73-80. [DOI:10.3758/BF03196141] [PMID]

[27] Gomes GdC, Teixeira-Salmela LF, Freitas FASd, Fonseca MLM, Pinheiro MdB, Morais VAdC, et al. Gait performance of the elderly under dual-task conditions: Review of instruments employed and kinematic parameters. Revista Brasileira de Geriatria e Gerontologia. 2016; 19(1):165-82. [DOI:10.1590/1809-9823.2016.14159]

[28] Krasovsky T, Lamontagne A, Feldman AG, Levin MF. Effects of walking speed on gait stability and interlimb coordination in younger and older adults. Gait \& Posture. 2014; 39(1):378-85. [DOI:10.1016/j.gaitpost.2013.08.011] [PMID] 